Medical Scope Journal (MSJ). 2019;1(1):16-20

Available from: https://ejournal.unsrat.ac.id/index.php/msj

\title{
Hubungan antara Beban Kerja dan Masa Kerja dengan Stres Kerja pada Security Check Point di PT Angkasa Pura I Bandar Udara Internasional Sam Ratulangi Manado
}

\author{
Larasati Aulia, Paul A. T. Kawatu, Fima L. F. G. Langi
}

Fakultas Kesehatan Masyarakat Universitas Sam Ratulangi Manado

Email: auliachristya23@gmail.com

\begin{abstract}
Decreased work productivity can be caused by working stress. There are factors that can affect working stress, including working time and workload. A 24-hour airport operating system requires employees who are security check points at the airport to be firm in conducting inspections with different characters, behaviors, and cultures each day. The heavy hours and flight routes ranging from domestic to overseas every day and excessive workload or work demands can potentially lead to occupational stress. This study was aimed to obtain the relationship between workload and working time and working stress among security check point employees at PT Angkasa Pura I Sam Ratulangi International Airport Manado. The total population of this study was 68 employees. The Spearman corelation test showed that there was a significant relationship with a positive correlation of strong category between workload and working stress among the security check point employees $(\mathrm{p}=0.000 ; \mathrm{r}=0.608)$. Moreover, there was a significant relationship between between working time and working stress $(p=0.001 ; r=-0.411)$. In conclusion, there was a significant positive relationship between work load and working stress and a significant negative relationship between working time and working stress among the employees on the security check point at PT Angkasa Pura I Sam Ratulangi International Airport Manado.
\end{abstract}

Keywords: workload, working period, work stress.

\begin{abstract}
Abstrak: Produktivitas kerja yang menurun dapat disebabkan oleh stres kerja. Terdapat faktor-faktor yang dapat memengaruhi stres kerja antara lain meliputi masa kerja serta beban kerja. Sistem operasi bandar udara selama 24 jam, menuntut para pekerja security check point di bandar udara harus tegas dalam melakukan pemeriksaan dengan karakter, perilaku, serta budaya yang berbeda tiap harinya. Padatnya jam dan rute penerbangan mulai dari domestik sampai ke luar negeri setiap harinya serta beban kerja atau tuntutan kerja yang berlebihan dapat berpotensi mengakibatkan stres kerja. Penelitian ini bertujuan untuk mengetahui hubungan antara beban kerja dan masa kerja dengan stres kerja pada security check point di PT Angkasa Pura I Bandar Udara Internasional Sam Ratulangi Manado. Populasi penelitian ini yaitu seluruh pekerja yang berjumlah 68 orang. Hasil uji statistik Spearman mendapatkan hubungan bermakna dengan korelasi positif kategori kuat antara beban kerja dengan stres kerja $(p=0,000 ; r=0,608)$. Selain itu terdapat hubungan berlawanan arah (negatif) antara masa kerja dengan stres kerja $(\mathrm{p}=0,001 ; \mathrm{r}=-0,411)$. Simpulan penelitian ini ialah pada security check point di PT Angkasa Pura I Bandar Udara Internasional Sam Ratulangi Manado terdapat hubungan bermakna yang positif antara beban kerja dengan stres kerja serta terdapat hubungan bermakna yang negatif antara masa kerja dengan stres kerja.
\end{abstract}

Kata kunci: beban kerja, masa kerja, stres kerja

\section{PENDAHULUAN}

Keselamatan dan kesehatan kerja adalah kegiatan untuk menjamin dan melin- dungi keselamatan dan kesehatan kerja serta penyakit akibat kerja, terciptanya tempat kerja yang efisien aman dalam 
perusahaan serta meningkatnya produktivitas kerja adalah sasaran penerapan K3. ${ }^{1}$ Menurut Sutrisno ${ }^{2}$ produktivitas kerja yang menurun dapat disebabkan oleh stres kerja. Keadaan stres dapat disebabkan oleh berbagai persoalan yang dialami individu dalam kehidupan keluarga, masyarakat, maupun di tempat kerja. ${ }^{3}$ Stres akibat kerja merupakan suatu hal seperti ketidakmampuan pekerja dalam menghadapi tuntutan tugas pekerjaan, yang dapat menyebabkan ketidaknyamanan dalam bekerja. Semua dampak dari stres kerja tersebut mengakibatkan menurunnya produktivitas kerja terhadap pekerja tersebut. ${ }^{4}$ Berdasarkan data dari World Health Organization (WHO) tahun 2014 sebesar 8\% negara mengalami penyakit yang diakibatkan oleh stres pekerjaan. ${ }^{5}$ Penelitian yang dilakukan oleh Labour Force Survey tahun 2014 melaporkan adanya 440.000 kasus stres akibat kerja di Inggris dengan angka kejadian sebanyak 1.380 kasus per 100.000 pekerja yang mengalami stres akibat kerja dan sebesar 35\% stres akibat kerja berakibat fatal. Selain itu diperkirakan hari kerja yang hilang sebesar $43 \%{ }^{6}$

Terdapat faktor-faktor yang dapat memengaruhi stres kerja antara lain faktor intrinsik seperti tuntutan tugas dan tuntutan fisik yang meliputi masa kerja, shift kerja, faktor peran individu dalam organisasi seperti beban kerja, konflik peran, faktor hubungan kerja, faktor pengembangan karier, faktor struktur organisasi serta faktor tuntutan dari luar pekerjaan. ${ }^{7}$ Hasil penelitian oleh Mohune ${ }^{8}$ menyatakan bahwa terdapat hubungan antara beban kerja dengan stres kerja pada Pekerja Unit Airport Rescue and Fire Fighting di Bandar Udara International Sam Ratulangi Manado.

Selain beban kerja, Tarwaka ${ }^{7}$ menyatakan bahwa masa kerja juga dapat memengaruhi terjadinya stres kerja. Hasil penelitian oleh Budiman ${ }^{9}$ menyatakan bahwa terdapat hubungan antara masa kerja dengan stres kerja pada pekerja kantor di Bandara Domini Osok Sorong. Masa kerja dan hubungannya dengan stres kerja merupakan masalah yang sangat penting untuk diperhatikan, demikian juga dengan masalah beban kerja yang berat dan berdampak terhadap stres kerja, karena tingkat beban kerja yang tinggi dan berkelanjutan berdampak pada stres kerja karyawan. ${ }^{7}$

Sistem operasi bandar udara selama 24 jam, menuntut para pekerja yang adalah security check point di bandar udara harus tegas dalam melakukan pemeriksaan dengan karakter, perilaku, serta budaya yang berbeda tiap harinya. Padatnya jam dan rute penerbangan mulai dari domestik sampai ke luar negeri setiap harinya serta beban kerja atau tuntutan kerja yang berlebihan dapat berpotensi mengakibatkan stres kerja. Berdasarkan hasil wawancara awal dengan bagian Safety Management System \& Occupational Health and Safety (SMS \& OSH) Bandar Udara Internasional Sam Ratulangi Manado didapatkan data pengukuran awal yang dilakukan oleh pihak SMS \& OSH yaitu security check point menunjukkan adanya stres kerja. Peneliti juga melakukan wawancara awal dengan pekerja bahwa adanya gejala stres kerja seperti gejala psikologis yaitu mudah marah dan cepat jenuh.

\section{METODE PENELITIAN}

Penelitian ini dilakukan terhadap seluruh pekerja security check point di PT Angkasa Pura I Bandar Udara Internasional Sam Ratulangi Manado yang berjumlah 68 pekerja. Jenis penelitian ialah kuantitatif dengan desain potong lintang. Instrumen pengumpulan data yang digunakan dalam penelitian ini ialah kuesioner stres kerja Health and Safety Executive dan kuesioner beban kerja NASA-TLX. Uji statistik yang dipakai ialah uji korelasi Spearman Rank.

\section{HASIL PENELITIAN}

Tabel 1 memperlihatkan karakteristik responden penelitian ini meliputi jenis kelamin, usia, dan pendidikan terakhir. Sebagian besar responden pekerja berjenis kelamin laki-laki sebanyak 39 orang (57\%). Sebagian besar responden pekerja berusia 21-25 tahun yaitu sebanyak 24 orang (35\%) dan paling sedikit pada kelompok usia 31- 
35 tahun yaitu sebanyak 9 orang (13\%). Responden yang berpendidikan SMA/ sederajat sebanyak 57 orang (84\%) dan responden dengan tingkat pendidikan $\mathrm{S} 1$ yaitu berjumlah 11 orang (16\%).

Tabel 1. Karakteristik responden

\begin{tabular}{llll}
\hline $\begin{array}{l}\text { Karakteristik } \\
\text { responden }\end{array}$ & $\mathbf{n}$ & $\mathbf{( \% )}$ & $\mathbf{N}(\%)$ \\
\hline $\begin{array}{l}\text { Jenis kelamin } \\
\text { Laki-laki }\end{array}$ & 39 & $(57)$ & $68(100)$ \\
Perempuan & 29 & $(43)$ & \\
Usia & & & $68(100)$ \\
$21-25$ tahun & 24 & $(35)$ & \\
26-30 tahun & 16 & $(24)$ & \\
$31-35$ tahun & 9 & $(13)$ & \\
$\geq 35$ tahun & 19 & $(28)$ & \\
Pendidikan terakhir & & & $68(100)$ \\
SMA & 57 & $(84)$ & \\
S1 & 11 & $(16)$ & \\
\hline
\end{tabular}

Tabel 2 menunjukkan bahwa terdapat hubungan searah antara beban kerja dengan stres kerja pada security check point di PT Angkasa Pura I Bandar Udara Internasional
Sam Ratulangi Manado. Terdapat korelasi bermakna dari beban kerja dengan stres kerja $(p=0,000<0,05)$. Nilai koefisien korelasi yaitu 0,608 menyatakan adanya korelasi dengan kategori kuat artinya beban kerja sangat memengaruhi stres kerja pekerja Pemeriksaan Keamanan Penumpang di Bandar Udara Internasional Sam Ratulangi Manado.

Tabel 3 menunjukkan adanya hubungan berlawanan arah atau negatif antara masa kerja dengan stres kerja pada security check point di PT Angkasa Pura I Bandar Udara Internasional Sam Ratulangi Manado. Hubungan tersebut bermakna dengan $\mathrm{p}=0,001<0,05$. Nilai koefisien korelasi yaitu -0,411 menyatakan adanya korelasi negatif dengan kekuatan hubungan sedang.

\section{BAHASAN}

Sebagian besar responden pekerja berjenis kelamin laki-laki sebanyak 39 orang (57\%) (Tabel 1) dikarenakan umumnya jenis pekerjaan security check point di PT Angkasa Pura I Bandar Udara Internasional Sam Ratulangi Manado lebih tepat dilakukan oleh laki-laki.

Tabel 2. Hubungan antara beban kerja dengan stres kerja pada security check point di PT Angkasa Pura I Bandar Udara Internasional Sam Ratulangi Manado

\begin{tabular}{lcccccccccccc}
\hline \multirow{1}{*}{ Beban Kerja } & \multicolumn{1}{c}{ Ringan } & \multicolumn{2}{c}{ Sedang } & \multicolumn{1}{c}{ Tinggi } & $\begin{array}{c}\text { Sangat } \\
\text { Tinggi }\end{array}$ & Total & $\%$ & $\begin{array}{c}\text { Nilai } \\
\text { r }\end{array}$ & $\begin{array}{c}\text { Nilai } \\
\mathbf{p}\end{array}$ \\
& $\mathrm{N}$ & $\%$ & $\mathrm{~N}$ & $\%$ & $\mathrm{~N}$ & $\%$ & $\mathrm{~N}$ & $\%$ & & & & \\
\hline Ringan & 6 & 8,8 & 6 & 8,8 & 0 & 0,0 & 0 & 0,0 & 12 & 17,6 & \multirow{2}{*}{0,608} & 0,000 \\
Sedang & 3 & 4,4 & 35 & 51,5 & 4 & 5,9 & 0 & 0,0 & 42 & 61,8 & & \\
Berat & 0 & 0,0 & 6 & 8,8 & 4 & 5,9 & 4 & 5,9 & 14 & 20,6 & & \\
Total & 9 & 13,2 & 47 & 69,1 & 8 & 11,8 & 4 & 5,9 & 68 & 100,0 & & \\
\hline
\end{tabular}

Tabel 3. Hubungan antara masa kerja dengan stres kerja pada security check point di PT Angkasa Pura I Bandar Udara Internasional Sam Ratulangi Manado

\begin{tabular}{|c|c|c|c|c|c|c|c|c|c|c|c|c|}
\hline \multirow{3}{*}{ Masa Kerja } & \multicolumn{6}{|c|}{ Stres Kerja } & \multirow{2}{*}{\multicolumn{2}{|c|}{$\begin{array}{c}\text { Sangat } \\
\text { Tinggi }\end{array}$}} & \multirow{3}{*}{ Total } & \multirow{3}{*}{$\%$} & \multirow{3}{*}{$\begin{array}{c}\text { Nilai } \\
\mathbf{r}\end{array}$} & \multirow{3}{*}{$\begin{array}{c}\text { Nilai } \\
\mathbf{p}\end{array}$} \\
\hline & \multicolumn{2}{|c|}{ Ringan } & \multicolumn{2}{|c|}{ Sedang } & \multicolumn{2}{|c|}{ Tinggi } & & & & & & \\
\hline & $\mathrm{N}$ & $\%$ & $\mathrm{~N}$ & $\%$ & $\mathrm{~N}$ & $\%$ & $\mathrm{~N}$ & $\%$ & & & & \\
\hline$<6$ tahun & 3 & 4,4 & 15 & 22,1 & 6 & 8,8 & 4 & 5,9 & 28 & 41,2 & - & \\
\hline 6-10 tahun & 0 & 0,0 & 20 & 29,4 & 2 & 2,9 & 0 & 0,0 & 22 & 32,4 & 0,411 & 0,001 \\
\hline$>10$ tahun & 6 & 8,8 & 12 & 17,6 & 0 & 0,0 & 0 & 0,0 & 18 & 26,5 & & \\
\hline Total & 9 & 13,2 & 47 & 69,1 & 8 & 11,8 & 4 & 5,9 & 68 & 100,0 & & \\
\hline
\end{tabular}


Hasil penelitian ini mendapatkan adanya hubungan searah antara beban kerja dengan stres kerja pada security check point di PT Angkasa Pura I Bandar Udara Internasional Sam Ratulangi Manado (Tabel 2). Tampaknya bahwa semakin tinggi beban kerja pekerja, maka stres kerjanya akan semakin tinggi pula atau semakin rendah beban kerja maka stres kerja pekerja akan semakin rendah pula. Terdapat korelasi yang bermakna antara beban kerja dengan stres kerja karena nilai signifikansi lebih kecil dari 0,05 yaitu $\mathrm{p}=$ 0,000. Demikian pula nilai koefisien korelasi yaitu 0,608 mengartikan adanya korelasi dengan kategori kuat artinya beban kerja sangat memengaruhi stres kerja pekerja Pemeriksaan Keamanan Penumpang di Bandar Udara Internasional Sam Ratulangi Manado. Hasil penelitian ini sejalan dengan penelitian oleh Mubariroh ${ }^{10}$ terhadap karyawan produksi di JTV Surabaya yang mendapatkan adanya hubungan bermakna antara beban kerja dengan stres kerja pada karyawan produksi.

Hasil penelitian ini mendapatkan adanya hubungan berlawanan arah atau negatif antara masa kerja dengan stres kerja pada security check point di PT Angkasa Pura I Bandar Udara Internasional Sam Ratulangi Manado (Tabel 3). Hubungan tersebut bermakna karena nilai signifikansi lebih kecil dari 0,05 yaitu $p=0,001$. Oleh karena itu dapat disimpulkan bahwa terdapat korelasi bermakna dari masa kerja dengan stres kerja. Nilai koefisien korelasi yaitu -0,411 menyatakan adanya korelasi negatif dengan kekuatan hubungan sedang. Semakin lama masa kerja individu tersebut, semakin rendah srtes kerja Sebaliknya masa kerja yang relatif singkat mempunyai stres kerja yang semakin tinggi.

Masa kerja dapat diartikan sebagai sepenggalan waktu yang agak lama dimana seseorang tenaga kerja masuk dalam satu wilayah tempat usaha sampai batas tertentu. $^{11}$ Menurut Tarwaka, ${ }^{4}$ masa kerja adalah suatu kurun waktu atau lamanya tenaga kerja itu bekerja di suatu tempat. Masa kerja yang lebih lama menunjukkan pengalaman yang lebih dibandingkan dengan rekan kerja lainnya, sehingga sering masa kerja atau pengalaman kerja menjadi pertimbangan sebuah perusahaan dalam mencari pekerja. $^{12}$

\section{SIMPULAN}

Berdasarkan hasil penelitian terhadap security check point di PT Angkasa Pura I Bandar Udara Internasional Sam Ratulangi Manado ini dapat disimpulkan bahwa terdapat hubungan bermakna antara beban kerja dengan stres kerja serta terdapat hubungan antara masa kerja dengan stres kerja.

Bagi security check point di PT Angkasa Pura I Bandar Udara Internasional Sam Ratulangi Manado disarankan agar lebih memperhatikan beban kerja yang diberikan kepada pekerja untuk mengendalikan stres kerja yang akan berdampak pada kinerja. Bagi Manajemen PT Angkasa Pura I Bandar Udara Internasional Sam Ratulangi Manado agar dapat membagi pekerjaan kepada beberapa orang, memberikan pelatihan sebelum melaksanakan pekerjaan, refreshing terhadap para pekerja tetap dilaksanakan. Bagi peneliti lain agar dapat mengembangkan penelitian ini dengan menganalisis faktor lainnya yang diduga mempengaruhi stres kerja.

\section{DAFTAR PUSTAKA}

1. Peraturan Pemerintah; Penerapan Sistem Manajemen Keselamatan dan Kesehatan Kerja. Peraturan Pemerintah Republik Indonesia Nomor 50 Tahun 2012.

2. Sutrisno E. Budaya Organisasi. Jakarta: Kencana Prenada Media Group, 2010.

3. Wahyudi. Manajemen Konflik dan Stres dalam Organisasi. Bandung: Alfabeta, 2017.

4. Tarwaka. Ergonomi Industri. Surakarta: Harapan Press, 2010.

5. World Health Organization. 2014. Protecting Workers Health. Geneva: World Health Organization Centre for Health Development, 2014.

6. Labour Force Survey. 2014. Work related stress, anxiety and depression statistic Great Britain. Available from: http://www.hse.gov.uk/statistics/causdi s/stress/. 
20 Medical Scope Journal (MSJ), Volume 1, Nomor 1, Juli-Desember 2019, hlm.16-20

7. Tarwaka. Ergonomi Industri Dasar-Dasar Pengetahuan Ergonomi dan Aplikasi di Tempat Kerja. Surakarta: Harapan Press, 2015.

8. Mohune P. Hubungan antara beban kerja dengan stres kerja pada pekerja Unit Airport Rescue and Fire Fighting di Bandar Udara International Sam Ratulangi Manado. 2019. Available from: http://www.ejournalhealth.com/ index.php/kesmas/article/view/791/776.

9. Budiman A. Hubungan Intensitas Kebisingan Dengan Stres Kerja Pada Pekerja
Kantor Bandara Domini Eduard Osok Sorong. 2014. Available from: http://repository.unhas.ac.id/.

10. Mubariroh. Hubungan antara beban kerja dan stres kerja pada Karyawan JTv di Surabaya. 2013. Available from: http: //uin.unanampel.surabaya/.

11. Suma'mur. Hiegiene Perusahan dan Keselamatan Kerja. Jakarta: CV Sagung Seto, 2009.

12. Rivai V. Manajemen Sumber Daya Manusia untuk Perusahaan dari Teori ke Praktik. Jakarta: Raja Grafindo Persada, 2009. 